\section{Ivory tower}

\section{A place to call our own.}

\section{Bruce Sterling}

Our problem was simple. We needed an academy, but professional careers in conventional science were out of the question for us. We were 10,000 physicists, entirely self-educated on the Internet.

Frankly, physics is a lot easier to learn than physicists used to let on. The ultimate size of the smallest particles, the origin and fate of the Universe - come on, who could fail to take a burning interest in those subjects? If we were genuinely civilized, that's all we would talk about. In the new world of open access, ultrawide broadband and gigantic storage banks, physics is just sort of sitting there. It's like a vast intellectual Tinkertoy! We cranky net-geeks had to find a way to devote every waking moment to our overpowering lust for physics. Of course, we demanded state support for our research efforts (just like real scientists do) but, alas, the bureaucrats wouldn't give us the time of day.

So to find time for our kind of science, we had to dump a few shibboleths. For instance, we never bother to 'publish': we just post our findings on weblogs, and if they get a lot of links, hey, we're the Most Frequently Cited. Tenure? Who needs that? Never heard of it! Doctorates, degrees, defending a thesis - don't know, don't need 'em, can't even be bothered!

Organizing ourselves was a snap. If you are a maths genius whose primary language is Malayalam and whose main enthusiasm is wave-particle duality, you stand out on the net like a buzzing hornet in a spiderweb. You're one in a million, pal — but in a world of ten billion people, there's 10,000 of us. We immediately started swapping everything we knew on collaborative weblogs.

As most of us were Indian and/or Chinese (most of everybody is Indian and/or Chinese) we established our Autodidacts' Academy on the sun-baked, sandstone flats of the desert of Rajasthan, not too far from the deserted Mughal utopia of Fatehpur Sikri. We were dreamy, workaholic utopians trying to wrest a living out of barren wilderness. Something like Mormons, basically. However, as it was the 2050s, we also had unlimited processing power, bandwidth, search engines, social software and opensource everything. How could we fail?

Basically, we recast human existence as a bioengineering problem. How do you move

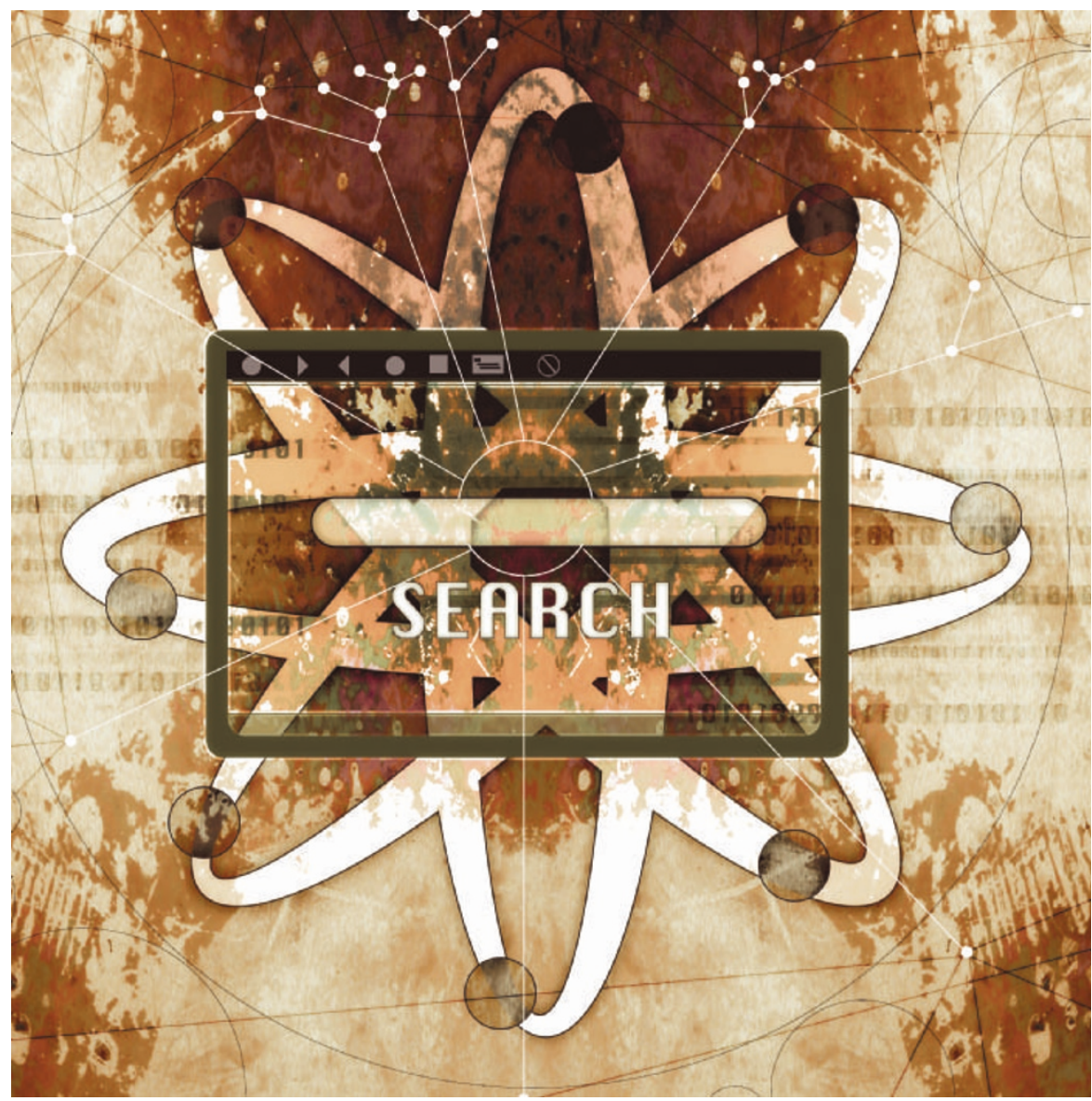

enough nutrient through human brain tissue to allow an entire city of people to blissfully contemplate supersymmetric M-branes? The solutions were already scattered through the online technical literature; we just Googled it all up and set it to work. Our energy is solar; water is distilled and recycled; and the ivory gleaming domes and spires of our physics ashram are computer-fabricated grit, glue and sawdust. All our lab equipment is made of garbage.

Our visitors are astounded to see (for instance) repurposed robotic vacuum cleaners equipped with tiller blades digging out our 150-kilometre accelerator tunnel. But why not? In the 2050s, even the junk is ultraadvanced, and nobody knows how to repair it. Any sufficiently advanced garbage is indistinguishable from magic.

Our daily diet, which is free of charge, is fully defined Physicist Chow. It's basically sewage, with its bioenergetic potential restored by genetically altered yeasts. Some diners fail to appreciate the elegant mathematical simplicity of this solution to the age-old problem of a free lunch. But if they don't get it, then they don't belong here with us, anyway.

There's no money and no banking here. Instead, every object is tracked by RFID tags and subjected to a bioenergetic, cost-benefit, eBay-style arbitrage by repurposed stockmarket buy-sell software agents. In practice, this means that when you need something new, you just pile up the things you don't want by your doorway until somebody shows up and gives you the thing you do want. Economists who visit here just flee screaming - but come on, was economics ever really a 'science'? We're with Rutherford: it's physics or it's stamp collecting!

You might imagine that women would find our monastic, geeky life unattractive, but our academy's crawling with co-eds. A few are female physicists - the usual proportion - but the rest are poets, lit. majors, anthropologists and gender studies mavens. These gals showed up to condemn our reductionalist, instrumental male values, but they swiftly found out that our home is ideal for consciousness-raising, encounter groups and performance art. So women now outnumber us three to two. That's not a problem. We don't bother them with our weird obsessions, they don't bother us with theirs, and whatever happens between us after dark is nobody's business.

We have a beautiful, spiritual thing going on here. Feel free to join us. Please, no more atomic-bomb fans. We know that atomic bombs are a dead simple, 100 -year-old technology. Anybody with a search engine, half a brain and a lot of time can tinker one up. But really, why even bother? It's beneath us!

Bruce Sterling is currently 'visionary in residence' at the Art Center College of Design in Pasadena. He also writes science fiction novels and maintains a daily weblog at http://blog.wired.com/sterling. 